\title{
ORIGINAL
}

\section{Effect of six-month lifestyle intervention on adiponectin, resistin and soluble tumor necrosis factor- $\alpha$ receptors in obese adolescents}

\author{
Fengyang Huang ${ }^{1)}$, Blanca Estela del-Río-Navarro ${ }^{2)}$, José Alfredo Pérez-Ontiveros ${ }^{1)}$, \\ Eliseo Ruiz-Bedolla ${ }^{3)}$, Omar Josué Saucedo-Ramírez ${ }^{2)}$, Santiago Villafaña ${ }^{4)}$, Guadalupe Bravo ${ }^{5)}$, \\ Patrick Mailloux-Salinas ${ }^{5)}$ and Enrique Hong ${ }^{5)}$ \\ 1) Laboratory of Pharmacology and Toxicology, Hospital Infántil de México Federico Gómez (HIMFG), Mexico City 06720, Mexico \\ 2) Department of Allergy, HIMFG, Mexico City 06720, Mexico \\ 3) Center Laboratories, HIMFG, Mexico City 06720, Mexico \\ 4) Superior School of Medicine, National Polytechnic Institute, Mexico City 11340, Mexico \\ 5) Department of Pharmacobiology, Centro de Investigación y de Estudios Avanzados del Instituto Politécnico Nacional, Mexico \\ City 14330, Mexico
}

\begin{abstract}
The aim of this study was to evaluate the effect of a six-month lifestyle intervention on adiponectin, resistin, and two soluble forms of tumor necrosis factor- $\alpha$ receptor (sTNFR) in obese adolescents. A total of 54 obese adolescents aged 10 to 16 years completed the program. Twenty-four adolescents with normal weight at baseline were used as a control group. Our results demonstrated that obese adolescents had abnormal lipid profile, homeostasis model assessment (HOMA) index, adiponectin level $(5.6 \pm 2.7 v s .7 .6 \pm 2.9 \mu \mathrm{g} / \mathrm{mL}, p=0.005)$ as well as resistin level $(31.0 \pm 9.0 v s .24 .3 \pm 8.5 \mathrm{ng} / \mathrm{mL}$, $p=0.003$ ), whereas levels of both sTNFRs were similar to those in normal weight subjects. After the six-month lifestyle intervention, obese adolescents had a slight but significant drop in standard deviation score-body mass index (SDS-BMI), a significant decrease in waist circumference, total cholesterol, triglycerides, HOMA index, as well as resistin, and a significant increase in adiponectin and high-density lipoprotein-cholesterol. In adolescents without decreased SDS-BMI, no change was observed in adipokines. Changes in adiponectin correlated negatively with changes in waist circumference $(\mathrm{r}=0.275, p=0.044)$. Changes in resistin correlated positively with changes in triglycerides $(\mathrm{r}=0.302, p=0.027)$. The study demonstrated the increase of resistin and the decrease of adiponectin in obese adolescents. Lifestyle intervention improved adipokine abnormalities in obese subjects.
\end{abstract}

Key words: Adiponectin, Resistin, Tumor necrosis factor- $\alpha$ receptor, Life-style intervention, Obese adolescents

THE PREVALENCE of childhood and adolescent obesity is increasing worldwide. Childhood obesity is directly linked to abnormalities in blood pressure, lipids, and insulin action in later life as well as to the risk of diabetes mellitus and cardiovascular diseases [1-2].

It is now well recognized that adipose tissue is an endocrine organ that secretes a variety of biologically active adipokines such as adiponectin, resistin

Submitted Apr. 6, 2014; Accepted Jun. 18, 2014 as EJ14-0157 Released online in J-STAGE as advance publication Jul. 17, 2014

Correspondence to: Blanca Estela del-Río-Navarro, Ph.D., Department of Allergy, Hospital Infantil de México Federico Gómez, Dr. Marquez No. 162, Mexico City 06720, Mexico. E-mail: blancadelrionavarro@gmail.com and tumor necrosis factor (TNF)- $\alpha$. Both adiponectin and resistin contribute to the pathophysiology of obesity-linked disorders through their ability to modulate inflammatory and metabolic process [3-4]. In most studies, concentrations of these adipokines are altered in the presence of obesity, with reduced adiponectin levels and increased resistin concentrations [5-7].

TNF- $\alpha$ is cytokine involved in regulation of the whole-body carbohydrate and lipid metabolism. One of main metabolic effects of TNF- $\alpha$ action is the development of insulin resistance [8-9]. Two cell surface TNF- $\alpha$ were describe in humans, TNFR1 (p60) and TNFR2 (p80), soluble forms of those receptors (sTNFR1 and sTNFR2) are present in plasma. Plasma 
TNF- $\alpha$ values are usually low and do not give the precise information about its auto- and paracrine action. It is supposed that circulation levels of these receptors are recognized markers of activity of TNF- $\alpha$ system [10]. However, TNFR implication in obesity is still a matter of debate. In human studies, increased or no change of plasma levels of both receptors were reported in previous studies [11-13].

It is widely recognized that lifestyle intervention with modification of dietary habits and physical activity is the most important measure to modify weight excess in childhood and adolescence [14-16]. Although several studies have been conducted to date on the effects of lifestyle modification on adipokines and inflammatory biomarkers [17-18], very few have focused on resistin and STNFR in obese adolescents. Therefore, the aims of this study were: 1) to compare adiponectin, resistin, sTNFR1 and sTNFR2 serum levels between obese adolescents and adolescents with normal body mass index (BMI), 2) to investigate changes in anthropometrics, lipid profiles, HOMA, adipokines after six-month lifestyle intervention, 3) to evaluate whether the observed changes in adipokines was associated with the changes in anthropometrics, lipid profiles and HOMA.

\section{Materials and Methods}

\section{Subjects}

Obese adolescents were consecutively recruited in Hospital Infantíl de México Federico Gómez. Obesity was defined as BMI in excess of the 95 percentile according to age and sex (using the percentile charts of the Center for Disease Control and Prevention for the assessment of somatic development in children and adolescents). Normal weight adolescents $(10<\mathrm{BMI}<85$ percentile) were invited from obese subject's friends including their classmates. Children with endocrine disorders, familial hyperlipidemia, hypertension, diabetes, pharmacological treatment were excluded from the study. The study protocol was approved by the Committee for Ethics and Control of Hospital Infantil de México Federico Gómez. Parents and children were informed as to the nature and purpose of the study. Parents gave their written informed consent. Children gave their consent verbally.

\section{Overview of the protocol}

All participants for the study were asked to fill out a questionnaire concerning their eating and exercise habits. Body weight was measured in underwear to the nearest $0.1 \mathrm{~kg}$ using a calibrated balance scale. Height was measured to the nearest centimeter using a rigid stadiometer. BMI was calculated as body weight in kilograms divided by the square of height in meters. Blood pressure was measured according to the guidelines of the National High Blood Pressure Education Program. Systolic and diastolic blood pressure were measured twice at the right arm after a 10-min rest in the supine position using a calibrated sphygmomanometer and then averaged. Waist circumference was measured at a level midway between the lower rib margin and iliac crest with the tape all around the body in horizontal position.

For analysis, $6 \mathrm{~mL}$ of blood was taken from the left cubital vein, which was a morning sample taken before breakfast (from 8:00 am to 9:00 am), after an overnight $12 \mathrm{hrs}$ fast. The serum for adiponectin, resistin, sTNFR1 and sTNFR2 analysis were frozen and kept at a temperature of $-70{ }^{\circ} \mathrm{C}$ until analysis was performed.

The concentrations of glucose, cholesterol, triglyceride and HDL-cholesterol were measured by standard enzymatic assay in our hospital's central laboratory using standard laboratory instruments (DimensionRXL, Dade, Behring, Germany). The concentration of insulin was determined by solid-phase, two-site chemiluminescent immunometric assay (Immulite, Diagnostic Products Corp., Los Angeles, CA). The serum concentrations of adiponectin and resistin were determined by enzyme-lined immunosorbent assay (ELISA; Millipore, USA). The concentrations of sTNFR1 and sTNFR2 were measured with commercially available ELISA kits (Bender MedSystems, Austria). Insulin resistance was calculated by homeostasis model assessment: HOMA-IR $=[$ insulin $(\mathrm{mU} / \mathrm{L})$ $\times$ glucose $(\mathrm{mM} / \mathrm{L})] / 22.5$. For all obese subjects, the protocol was repeated at 6 monthly intervals. The normal-weight subjects were studied only at baseline.

\section{Lifestyle intervention}

Of the total 70 obese subjects were recruited, 54 subjects completed 6 months of follow-up, with 16 losses $(22.9 \%)$. Several subjects did not continue the protocol for unspecified reasons and could not be reached for follow-up; several subjects were not able to continue because they changed address and lived far away from the hospital. Therefore, the baseline values of only 54 subjects, who completed intervention, were presented and compared with normal-weight healthy subjects. 
All of the participants with obesity attended a 6-month lifestyle intervention program, which was directed by a registered nutritionist and supervised by a physician. Compliance with the lifestyle changes was achieved by a combination of good dietary practices, physical activity, behavioral counseling (in consultation with a clinical psychologist), and active involvement of the family. During the course, participants received diet instruction and physical training once a week.

The parents of the adolescents participated in 4 intensive lifestyle support sessions (once a week in the first month), then 1 monthly 15 -minute individual telephone sessions. These sessions focused on lifestyle knowledge and skills as follows: family focused healthy eating with specific core food serve recommendations, monitoring, label reading, snacks, modifying recipes, being active in a variety of ways, roles and responsibilities around eating, managing appetite, self-esteem, and teasing.

The main aim of obesity treatment is to achieve an ideal weight for a given height, at the same time ensuring the required supply of nutrients to avoid interfering with growth. Moderate obesity requires nutritional intervention, with a low-calorie diet calculated on the basis of age and aimed at maintaining body weight while not impairing growth, thus achieving a decrease in BMI. The nutrition counseling was based on healthy food selections, emphasizing reduced carbohydrate and fat consumption. The aims were to reduce dietary fat as well as sugar-based carbonated drink intake, together with increase in vegetables and fruits with rich fiber. Severe obesity may require restriction of diet to $20 \%$ of the diet recommended for a healthy age- and sex-matched child. The severe obese subjects are offered an optimized balanced diet prepared according to guidelines $(30 \%, 15 \%$ and $55 \%$ of the total energy content from fat, proteins and carbohydrates, respectively), with an allowed energy intake of 1,250-1,800 kcal per day, depending on height and sex. Additionally, the obese children and family are required to participate in theoretical and practical lessons on healthy eating, physical activity and behavior change skills based on the cognitive-behavioral theory. The subjects were advised to perform brisk walking for 30 min daily during the first two weeks. Thereafter, the duration of activity was progressively increased to one hour by the third week. Participants were also encouraged to undertake moderate-intensity physical activity (cycling, jogging, and swimming) at least 5 times per week in addition to the daily walking.

\section{Statistical analysis}

Statistical analysis was performed with the use of the computer program SPSS 17.0. The unpaired Student's $t$-test and the Mann-Whitney U test were used for variables normally distributed or not normally distributed, respectively. The data are presented as mean values with standard deviations. Baseline and post-intervention values were compared using the paired $t$-test or the Wilcoxon signed ranks test variables with distributions significantly deviating from normal. Changes in variables after intervention were calculated as values after intervention subtract values at baseline. Correlation between variables at baseline or changes before and after intervention was analyzed by Pearson. Variable changes after intervention $(\%)=($ value after intervention - value at baseline) $\times 100 /$ value at baseline. All $p$ value resulted from 2 -side statistical tests and $\leq 0.05$ was considered statistically significant.

\section{Results}

\section{General characteristics of the study population at baseline}

The clinical and biochemical characteristics of these two groups are shown in Table 1. The two groups did not differ in gender distribution, age, and tanner stage. Compared with normal-weight adolescents, obese adolescents had significantly higher levels of weight, BMI, BMI percentile, and SDS-BMI. The obese also showed higher levels in blood pressure, triglycerides, insulin and HOMA-IR and reduced in HDL-cholesterol. The levels of total cholesterol and glucose were numerically higher in obese adolescents compared with those in normal-weight adolescents. The obese group also presented significantly higher levels of resistin and lower levels of adiponectin in comparison with normal-weight subjects, no difference in sTNFR1 and sTNFR2 was observed between two studied groups (Table 1).

The gender difference in the two studied groups has been evaluated, the boys with normal weight showed numerical higher levels in SBP than the girls $(p=0.052)$. In obese adolescents, the girls presented higher BMI than the boys $(p=0.044)$. Moreover, obese girls showed tendency in reduced levels of HDL-cholesterol $(p=0.062)$ than the obese boys (Table 2). No gender-related difference in other anthropometrics, lipid profile or adipokines was observed in studied subjects (Table 2). 
Table 1 The characteristics of the studied groups at baseline

\begin{tabular}{lccc}
\hline & $\begin{array}{c}\text { Normal weight } \\
\mathrm{n}=24\end{array}$ & $\begin{array}{c}\text { Obese at baseline } \\
\mathrm{n}=54\end{array}$ & $p$ value \\
\hline Age (year) & $13.5 \pm 2.1$ & $13.6 \pm 1.3$ & 0.780 \\
Sex (female/male) & $13 / 11$ & $22 / 32$ & 0.277 \\
Tanner stage $(1 / 2 / 3 / 4)$ & $6 / 7 / 4 / 7$ & $10 / 23 / 13 / 8$ & 0.559 \\
Weight $(\mathrm{kg})$ & $47.6 \pm 9.8$ & $73.7 \pm 14.1$ & $<0.001$ \\
Height $(\mathrm{cm})$ & $155.8 \pm 10.5$ & $154.2 \pm 7.8$ & 0.457 \\
BMI $\left(\mathrm{kg} / \mathrm{m}^{2}\right)$ & $19.4 \pm 2.2$ & $30.9 \pm 5.6$ & $<0.001$ \\
BMI percentile & $53.9 \pm 19.5$ & $97.5 \pm 1.8$ & $<0.001$ \\
SDS-BMI & $0.1 \pm 0.5$ & $2.1 \pm 0.3$ & $<0.001$ \\
Heart rate $($ beat/min) & $73.9 \pm 4.0$ & $79.2 \pm 7.1$ & 0.001 \\
SBP $(\mathrm{mmHg})$ & $98.3 \pm 8.2$ & $106.4 \pm 9.4$ & 0.001 \\
DBP $(\mathrm{mmHg})$ & $63.8 \pm 6.5$ & $67.3 \pm 7.5$ & 0.050 \\
HDL-cholesterol $(\mathrm{mg} / \mathrm{dL})$ & $50.3 \pm 15.9$ & $43.1 \pm 9.5$ & 0.016 \\
Total cholesterol $(\mathrm{mg} / \mathrm{dL})$ & $156.3 \pm 29.3$ & $171.3 \pm 48.0$ & 0.160 \\
Triglycerides $(\mathrm{mg} / \mathrm{dL})$ & $91.4 \pm 39.4$ & $144.9 \pm 58.2$ & $<0.001$ \\
Glucose $(\mathrm{mg} / \mathrm{dL})$ & $85.2 \pm 8.1$ & $91.0 \pm 16.5$ & 0.104 \\
Insulin $(\mathrm{mU} / \mathrm{L})$ & $7.0 \pm 4.6$ & $25.6 \pm 12.9$ & $<0.001$ \\
HOMA & $1.5 \pm 1.0$ & $5.9 \pm 3.4$ & $<0.001$ \\
Adiponectin $(\mu \mathrm{g} / \mathrm{mL})$ & $7.6 \pm 2.9$ & $5.6 \pm 2.7$ & 0.005 \\
\hline Resistin $(\mathrm{ng} / \mathrm{mL})$ & $24.3 \pm 8.5$ & $31.0 \pm 9.0$ & 0.003 \\
sTNFR1 $(\mathrm{ng} / \mathrm{mL})$ & $1.0 \pm 0.1$ & $1.2 \pm 0.2$ & 0.469 \\
sTNFR2 $(\mathrm{ng} / \mathrm{mL})$ & $37.2 \pm 3.6$ & $32.9 \pm 4.3$ & 0.535 \\
\hline Vals & & & \\
\hline
\end{tabular}

Values are shown as mean and standard deviation.

BMI, body mass index; SDS-BMI, standard derivation score-body mass index; SBP, systolic blood pressure; DBP, diastolic blood pressure; HDL, high-density lipoprotein; HOMA, homeostasis model assessment; sTNFR, soluble form of tumor necrosis factor- $\alpha$ receptor.

Table 2 Gender difference in the studied groups at baseline

\begin{tabular}{|c|c|c|c|c|c|c|}
\hline & \multicolumn{3}{|c|}{ Normal Weight } & \multicolumn{3}{|c|}{ Obese at baseline } \\
\hline & boys & girls & $p$ value & boys & girls & $p$ value \\
\hline $\mathrm{n}$ & 11 & 13 & & 32 & 22 & \\
\hline Age (year) & $13.6 \pm 2.1$ & $13.4 \pm 2.2$ & 0.78 & $13.4 \pm 1.4$ & $13.9 \pm 1.2$ & 0.136 \\
\hline Tanner stage $(1 / 2 / 3 / 4)$ & $2 / 3 / 3 / 3$ & $4 / 4 / 1 / 4$ & 0.613 & $9 / 13 / 6 / 4$ & $1 / 10 / 7 / 4$ & 0.669 \\
\hline Weight (kg) & $48.2 \pm 11.2$ & $47.1 \pm 8.9$ & 0.795 & $71.7 \pm 15.1$ & $76.6 \pm 12.2$ & 0.217 \\
\hline Height $(\mathrm{cm})$ & $156.8 \pm 11.2$ & $155.0 \pm 10.1$ & 0.679 & $155.2 \pm 8.3$ & $152.9 \pm 7.0$ & 0.287 \\
\hline $\operatorname{BMI}\left(\mathrm{kg} / \mathrm{m}^{2}\right)$ & $19.3 \pm 2.3$ & $19.4 \pm 2.1$ & 0.895 & $29.7 \pm 5.6$ & $32.8 \pm 5.2$ & 0.044 \\
\hline BMI percentile & $52.8 \pm 20.7$ & $54.9 \pm 19.1$ & 0.794 & $97.3 \pm 1.7$ & $97.7 \pm 1.9$ & 0.433 \\
\hline SDS-BMI & $0.07 \pm 0.57$ & $0.13 \pm 0.51$ & 0.789 & $2.02 \pm 0.33$ & $2.10 \pm 0.33$ & 0.383 \\
\hline Heart rate (beat/min) & $73.3 \pm 4.6$ & $74.5 \pm 3.4$ & 0.475 & $79.8 \pm 6.7$ & $78.3 \pm 7.6$ & 0.459 \\
\hline $\mathrm{SBP}(\mathrm{mmHg})$ & $101.8 \pm 8.7$ & $95.4 \pm 6.6$ & 0.052 & $105.5 \pm 9.3$ & $107.7 \pm 9.6$ & 0.39 \\
\hline DBP (mmHg) & $65.4 \pm 6.9$ & $62.3 \pm 6.0$ & 0.243 & $66.5 \pm 7.5$ & $68.4 \pm 7.5$ & 0.352 \\
\hline HDL-cholesterol (mg/dL) & $48.8 \pm 15.1$ & $51.5 \pm 17.2$ & 0.695 & $45.1 \pm 10.5$ & $40.2 \pm 7.0$ & 0.062 \\
\hline Total cholesterol (mg/dL) & $156.1 \pm 28.8$ & $156.5 \pm 30.8$ & 0.976 & $174.5 \pm 52.7$ & $166.8 \pm 40.8$ & 0.567 \\
\hline Triglycerides (mg/dL) & $89.0 \pm 51.5$ & $93.4 \pm 27.4$ & 0.792 & $134.5 \pm 49.4$ & $160.0 \pm 67.3$ & 0.114 \\
\hline Glucose (mg/dL) & $86.6 \pm 9.0$ & $83.9 \pm 7.3$ & 0.423 & $91.0 \pm 14.0$ & $91.0 \pm 19.9$ & 1 \\
\hline Insulin (mU/L) & $7.6 \pm 3.6$ & $6.5 \pm 5.4$ & 0.583 & $24.0 \pm 12.8$ & $27.9 \pm 12.9$ & 0.286 \\
\hline HOMA & $1.6 \pm 0.9$ & $1.4 \pm 1.2$ & 0.536 & $5.5 \pm 3.1$ & $6.4 \pm 3.7$ & 0.342 \\
\hline Adiponectin $(\mu \mathrm{g} / \mathrm{mL})$ & $6.7 \pm 2.6$ & $8.4 \pm 2.9$ & 0.149 & $5.5 \pm 2.7$ & $5.8 \pm 2.7$ & 0.755 \\
\hline Resistin (ng/mL) & $22.9 \pm 8.6$ & $25.4 \pm 8.6$ & 0.493 & $30.9 \pm 9.0$ & $31.1 \pm 9.1$ & 0.924 \\
\hline sTNFR1 (ng/mL) & $1.0 \pm 0.2$ & $0.9 \pm 0.4$ & 0.538 & $1.4 \pm 0.4$ & $1.0 \pm 0.1$ & 0.356 \\
\hline sTNFR2 (ng/mL) & $39.6 \pm 4.2$ & $35.2 \pm 5.8$ & 0.554 & $31.1 \pm 5.2$ & $35.6 \pm 7.5$ & 0.614 \\
\hline
\end{tabular}

Values are shown as mean and standard deviation. 
Table 3 The Pearson correlation between aidpokines and anthropometric variables or metabolic profile in all subjects at baseline

\begin{tabular}{lcccc}
\hline & Adiponectin & Resistin & sTNFR1 & sTNFR2 \\
\hline Age & -0.049 & $0.280^{*}$ & -0.028 & -0.046 \\
Weight & $-0.300^{* *}$ & $0.394^{* *}$ & -0.004 & 0.088 \\
Height & 0.084 & 0.064 & -0.114 & 0.019 \\
BMI & $-0.349^{* *}$ & $0.397^{* *}$ & 0.038 & 0.066 \\
SDS-BMI & $-0.343^{* *}$ & $0.373^{* *}$ & 0.067 & 0.056 \\
BMI percentile & $-0.290^{*}$ & $0.335^{* *}$ & 0.069 & 0.081 \\
HR & -0.182 & $0.245^{*}$ & 0.167 & 0.003 \\
SBP & $-0.359^{* *}$ & -0.031 & 0.009 & -0.08 \\
DBP & -0.192 & -0.035 & 0.147 & -0.041 \\
HDL-cholesterol & $0.309^{* *}$ & $-0.264^{*}$ & 0.065 & 0.056 \\
Cholesterol & -0.13 & 0.048 & -0.063 & -0.102 \\
Triglycerides & $-0.268^{*}$ & 0.133 & -0.165 & -0.075 \\
Glucose & -0.079 & -0.043 & -0.026 & 0.034 \\
Insulin & $-0.311^{* *}$ & $0.294^{* *}$ & -0.019 & -0.097 \\
HOMA & $-0.288^{*}$ & $0.252^{*}$ & -0.025 & -0.099 \\
\hline$* 00.05{ }^{* *}$ & & & &
\end{tabular}

${ }^{*} p \leq 0.05,{ }^{* *} p \leq 0.01$

\section{Correlation among variables in all participants at baseline}

Pearson analysis was performed in all studied subjects at baseline. The values of adiponectin were associated significantly with weight, BMI, SDS-BMI, BMI percentile, systolic blood pressure, triglycerides, insulin and HOMA in negative manner and with HDLcholesterol in positive manner (Table 3). The levels of resistin were associated with age, weight, BMI, SDSBMI, BMI percentile, heart rate, insulin and HOMA in positive way and with HDL-cholesterol in negative way (Table 3). No significant correlation was observed among the receptors of TNF- $\alpha$ and anthropometrics, lipid profile and HOMA (Table 3).

\section{Effect of six-month lifestyle intervention in obese adolescents}

Of the all obese adolescents who completed the program, $38(70.4 \%)$ attained a decrease in standard derivation score-body mass index (SDS-BMI), while 16 (29.6\%) maintained or increased their SDS-BMI. The clinical parameters of these two subgroups were shown in Table 4.

At baseline, gender, pubertal stage, age, BMI, BMI percentile, and SDS-BMI did not differ significantly between the adolescents with and without reduced SDS-BMI. No difference of systolic and diastolic blood pressure, lipid profile, insulin and HOMA between the two subgroups except the higher heart rate in obese adolescents with stable or increased SDS-BMI (Table 4).
No statistical difference in adiponectin, resistin and two receptors of TNF was observed in these two obese subgroups at baseline.

After six-month lifestyle modification, in the obese adolescents with decreased SDS-BMI, a significant reduction of total cholesterol, triglycerides, glucose, insulin, as well as HOMA and resistin was observed. Furthermore, concentrations of HDL-cholesterol and adiponectin increased significantly (Table 4). No changes were found in TNFR1 and TNFR2. In the obese adolescents with stable or increased SDS-BMI, a significant slight increase was observed in BMI, BMI percentile and SDS-BMI before and after intervention. No significant change was observed in lipid profile, insulin, HOMA, and adipokines (Table 4).

The gender effect of lifestyle intervention was also estimated in obese adolescents with reduced SDS-BMI (Table 5). Girls were older and had a more advanced pubertal development than boys. After six-month lifestyle intervention, girls had more reductions in weight, BMI, BMI percentile and SDS-BMI than boys. However, no significantly different effects between boys and girls were observed in lipid profile, insulin resistance and adipokines except for diastolic blood pressure with more drops for girls (Table 5).

\section{Correlations of the magnitude of changes between different parameters}

Regarding all 54 patients who completed six-month lifestyle intervention, changes in adiponectin corre- 
Table 4 The characteristics of the obese subjects with or without decreased SDS-BMI before and after 6-month lifestyle intervention

\begin{tabular}{|c|c|c|c|c|c|c|}
\hline & \multicolumn{3}{|c|}{ SDS-BMI decreased } & \multicolumn{3}{|c|}{ SDS-BMI stable or increased } \\
\hline $\mathrm{n}$ & \multicolumn{3}{|c|}{38} & \multicolumn{3}{|c|}{16} \\
\hline Age (y) & \multicolumn{3}{|c|}{$13.9 \pm 1.7$} & \multicolumn{3}{|c|}{$13.5 \pm 1.2$} \\
\hline $\operatorname{Sex}(\mathrm{F} / \mathrm{M})$ & \multicolumn{3}{|c|}{$14 / 24$} & \multicolumn{3}{|c|}{$8 / 8$} \\
\hline \multirow[t]{2}{*}{ Tanner Stage (/1/2/3/4) } & \multicolumn{3}{|c|}{$8 / 15 / 10 / 5$} & \multicolumn{3}{|c|}{$2 / 8 / 3 / 3$} \\
\hline & Baseline & After 6-month & $p$ value & Baseline & After 6-month & $p$ value \\
\hline BMI $\left(\mathrm{kg} / \mathrm{m}^{2}\right)$ & $30.9 \pm 6.0$ & $28.8 \pm 4.5$ & 0.001 & $31.1 \pm 5.0$ & $33.0 \pm 6.1$ & 0.002 \\
\hline BMI percentile & $97.5 \pm 1.7$ & $95.9 \pm 2.9$ & $<0.001$ & $97.4 \pm 1.9$ & $97.9 \pm 1.6$ & 0.008 \\
\hline SDS-BMI & $2.05 \pm 0.3$ & $1.84 \pm 0.3$ & $<0.001$ & $2.06 \pm 0.4$ & $2.15 \pm 0.4$ & 0.002 \\
\hline Waist circumference (cm) & $98.6 \pm 11.4$ & $94.4 \pm 10.9$ & $<0.001$ & $103.0 \pm 15.8$ & $104.1 \pm 12.7$ & 0.566 \\
\hline Heart rate (beat/min) & $77.7 \pm 6.3$ & $78.1 \pm 6.9$ & 0.517 & $82.8 \pm 7.6$ & $79.2 \pm 5.3$ & 0.057 \\
\hline $\mathrm{SBP}(\mathrm{mmHg})$ & $105.5 \pm 9.7$ & $105.1 \pm 8.6$ & 0.842 & $108.4 \pm 8.5$ & $106.2 \pm 9.4$ & 0.323 \\
\hline $\mathrm{DBP}(\mathrm{mmHg})$ & $66.5 \pm 7.3$ & $66.3 \pm 6.8$ & 0.847 & $69.1 \pm 7.8$ & $67.5 \pm 9.8$ & 0.57 \\
\hline HDL-cholesterol (mg/dL) & $43.4 \pm 10.8$ & $48.6 \pm 8.8$ & 0.001 & $42.4 \pm 5.6$ & $44.4 \pm 8.5$ & 0.443 \\
\hline Total cholesterol (mg/dL) & $177.2 \pm 53.2$ & $158.0 \pm 33.4$ & 0.001 & $157.5 \pm 29.4$ & $156.5 \pm 23.3$ & 0.881 \\
\hline Triglycerides (mg/dL) & $144.8 \pm 65.6$ & $129.5 \pm 51.4$ & 0.018 & $144.9 \pm 36.3$ & $146.2 \pm 48.4$ & 0.887 \\
\hline Glucose (mg/dL) & $91.6 \pm 16.3$ & $84.7 \pm 8.9$ & 0.02 & $89.6 \pm 17.2$ & $86.3 \pm 10.3$ & 0.33 \\
\hline Insulin (mU/L) & $25.4 \pm 12.4$ & $17.4 \pm 9.4$ & $<0.001$ & $26.1 \pm 14.4$ & $22.7 \pm 10.0$ & 0.105 \\
\hline HOMA & $5.8 \pm 3.0$ & $3.7 \pm 3.0$ & $<0.001$ & $6.1 \pm 4.3$ & $4.9 \pm 2.4$ & 0.121 \\
\hline Adiponectin $(\mu \mathrm{g} / \mathrm{mL})$ & $5.5 \pm 2.4$ & $7.6 \pm 3.6$ & $<0.001$ & $5.9 \pm 3.3$ & $5.8 \pm 2.5$ & 0.788 \\
\hline Resistin (ng/mL) & $30.5 \pm 9.3$ & $27.0 \pm 6.7$ & $<0.001$ & $32.3 \pm 8.2$ & $29.8 \pm 6.8$ & 0.248 \\
\hline sTNFR1 (ng/mL) & $1.2 \pm 0.3$ & $1.2 \pm 0.1$ & 0.843 & $1.1 \pm 0.1$ & $1.3 \pm 0.2$ & 0.054 \\
\hline sTNFR2 (ng/mL) & $31.3 \pm 5.3$ & $32.3 \pm 5.5$ & 0.622 & $36.9 \pm 7.3$ & $40.8 \pm 9.0$ & 0.344 \\
\hline
\end{tabular}

Values are shown as mean and standard deviation.

Table 5 The gender effect of lifestyle intervention in the obese adolescents with decreased SDS-BMI

\begin{tabular}{|c|c|c|c|}
\hline & Boys & Girls & $p$ value \\
\hline $\mathrm{n}$ & 24 & 14 & \\
\hline Age (y) & $13.2 \pm 1.1$ & $14.1 \pm 1.1$ & 0.017 \\
\hline \multirow[t]{2}{*}{ Tanner Stage $(/ 1 / 2 / 3 / 4)$} & $8 / 10 / 4 / 2$ & $0 / 5 / 6 / 3$ & 0.006 \\
\hline & \multicolumn{2}{|c|}{ Variable changes (\%) } & \\
\hline Weight (kg) & $1.3 \pm 4.4$ & $-6.5 \pm 8.2$ & 0.001 \\
\hline Height (cm) & $2.3 \pm 2.1$ & $2.4 \pm 3.8$ & 0.915 \\
\hline BMI $\left(\mathrm{kg} / \mathrm{m}^{2}\right)$ & $-3.2 \pm 3.9$ & $-10.3 \pm 11.2$ & 0.007 \\
\hline BMI percentile & $-0.9 \pm 1.1$ & $-2.7 \pm 2.7$ & 0.006 \\
\hline SDS-BMI & $-6.5 \pm 5.6$ & $-16.5 \pm 12.6$ & 0.002 \\
\hline Waist circumference $(\mathrm{cm})$ & $-4.7 \pm 4.1$ & $-3.4 \pm 4.0$ & 0.346 \\
\hline Heart rate (beat/min) & $0.5 \pm 12.9$ & $4.9 \pm 12.8$ & 0.318 \\
\hline $\mathrm{SBP}(\mathrm{mmHg})$ & $2.7 \pm 11.0$ & $-3.5 \pm 12.7$ & 0.121 \\
\hline $\mathrm{DBP}(\mathrm{mmHg})$ & $3.9 \pm 12.8$ & $-5.1 \pm 10.9$ & 0.033 \\
\hline HDL-cholesterol (mg/dL) & $14.3 \pm 19.2$ & $16.1 \pm 20.9$ & 0.796 \\
\hline Total cholesterol (mg/dL) & $-9.6 \pm 15.7$ & $-5.2 \pm 15.0$ & 0.403 \\
\hline Triglycerides (mg/dL) & $-3.9 \pm 30.4$ & $-5.7 \pm 24.6$ & 0.851 \\
\hline Glucose (mg/dL) & $-7.4 \pm 13.6$ & $-2.5 \pm 15.7$ & 0.345 \\
\hline Insulin (mU/L) & $-29.6 \pm 22.3$ & $-22.2 \pm 31.5$ & 0.452 \\
\hline HOMA & $-33.9 \pm 25.9$ & $-22.2 \pm 42.6$ & 0.365 \\
\hline Adiponectin $(\mu \mathrm{g} / \mathrm{mL})$ & $83.6 \pm 150.1$ & $38.8 \pm 62.3$ & 0.297 \\
\hline Resistin (ng/mL) & $-6.4 \pm 33.7$ & $-5.5 \pm 19.7$ & 0.931 \\
\hline sTNFR1 (ng/mL) & $26.0 \pm 15.2$ & $38.9 \pm 18.2$ & 0.593 \\
\hline sTNFR2 (ng/mL) & $-3.0 \pm 8.3$ & $23.1 \pm 26.5$ & 0.362 \\
\hline
\end{tabular}

Values are shown as mean and standard deviation. 


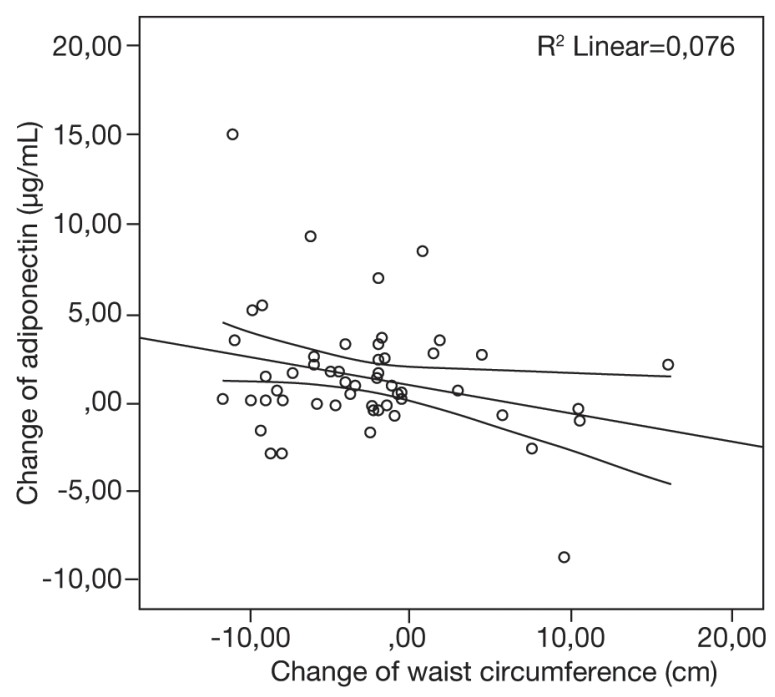

Fig. 1 The significant correlation between the changes in adiponectin and changes in waist circumference in obese adolescents after six-month lifestyle intervention $(n=54)$.

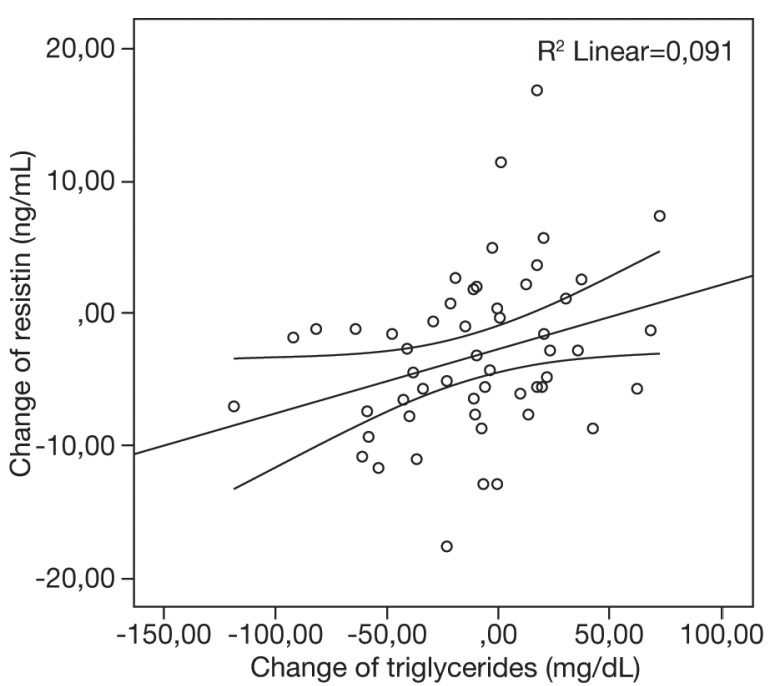

Fig. 2 The significant correlation between changes in resistin and changes in triglycerides in obese adolescents after six-month lifestyle intervention $(n=54)$. lated negatively with changes in waist circumference $(\mathrm{r}=-0.275, p=0.044$, Fig. 1). Changes in resistin correlated positively with changes in triglycerides $(\mathrm{r}=0.302$, $p=0.027$, Fig. 2). However, no significant correlation was observed between changes in adipokines and changes in other anthropometric parameters, metabolic profile, and HOMA (data not shown).

\section{Discussion}

This study showed that lifestyle modification in obese adolescents, even with slight but significant drop in SDS-BMI, determined positive changes in clinical and metabolic parameters. More importantly, SDSBMI reduction after intervention in obese adolescents led to favorable changes of adiponectin and resistin, in particular, the concentration of adiponectin recovered to normal level after intervention. Furthermore, the beneficial changes in waist circumference and triglycerides were associated with changes in adiponectin and resistin in obese adolescents.

Resistin is an adipocyte-secreted protein that has been shown to reduce insulin action in mice; however, its function in humans is still unclear [19]. The serum level of resistin in obese subjects was reported controversially in children. In the present study, resistin levels were higher in our obese adolescents than those in controls. Similar results have been observed in most studies with children [5, 20-22], except one that found no difference in resistin levels between obese and lean children [23]. We observed significant correlations between resistin and BMI or markers of insulin resistance at baseline, which is in agreement with one study reported in children [22]. There are controversies with regard to the correlation between resistin and insulin sensitivity in humans: several clinical studies on obese subjects have demonstrated that resistin is positively correlated to insulin-resistance [24], while other population studies disproved these remarks - resistin was not correlated to insulin-resistance in Pima Indians [26] or healthy normal-weight individuals [27]. Therefore, more studies are needed to solve this inconsistence.

The effect of lifestyle intervention on resistin concentrations in children has been scarcely reported and there is controversial information about its variations after intervention. In our present study, the significant reduction in resistin was observed after intervention. In agreement with our results, a very recent study with morbidly obese teenagers, significant decrement in resistin was observed after 8 weeks of aerobic exercise training [27]. In contrast, resistin levels in obese children after 1 year of weight loss did not show any differences between lean and obese [28]. Similarly, resistin did not show any significant change after 9-month program in obese adolescents [5]. We did not find any significant correlation between changes in resistin and changes in insulin resistance, which is in agreement with a previous longitudinal analysis in obese children [28]. There are also dif- 
ferent results, for example, the increased resistin levels were reported after individualized exercise training program or energy restriction and training program in obese adolescent boys, and the changes of resistin were significantly correlated with changes of insulin sensitivity [29]. Thus these divergent observations emphasize that the status and the pathophysiological role of resistin in obesity and insulin resistance are not yet clearly established. Moreover, our results showed that the reductions in resistin were correlated significantly with the decrease in triglycerides, indicating its important regulatory roles in atherosclerosis and cardiovascular diseases $[19,28]$. Finally, no relationship was observed between adiponectin and resistin in our present study. The lack of association is quite common in studies investigating children and adults $[5,20]$. Although both adipokines may have specific functions in metabolism related to obesity, their functions may be distinctly different and often unrelated.

In the present study, the lifestyle modification led to significant changes in body composition and improved insulin sensitivity. This was associated with an increase in adiponectin. A rise in total adiponectin concentrations has already been reported in obese children and adolescents after a lifestyle intervention [21, 29-33]. The rise in adiponectin could contribute to the improving of insulin sensitivity and the decreasing of atherogenesis associated with obesity [7]. In accordance with previous studies in children, we found that the increased concentrations in adiponectin were accompanied by the reduction in weight loss, BMI, systolic blood pressure, triglycerides, insulin resistance, and the increase in HDL-cholesterol. Furthermore, the enhancement of adiponectin (38.2\% $v s$. baseline) in the obese adolescents with decreased SDS-BMI almost reached to its normal levels in subjects with normal weight, although the obese subjects were still obese after intervention compared to the normal weight group, indicating that the serum adiponectin levels exhibited particular sensitivity to changes in body weight. It has been reported that adiponectin levels are significantly increased by $51.6 \%$ in the obese girls after the two-month intervention program with diet restriction and individualized [34]. This current study lasted 6 months; however, the duration of the time necessary to produce sustainable and stable changes after intervention to improve adiponectin in obese adolescents warrants more investigation. It has been shown that $50 \%$ of the patients regained the lost weight during the follow-up period (six month after weight loss) [35]. Future long-term longitudinal studies are needed to determine whether or not the lifestyle induced amendment of adipokine profile in adolescents translates into slower development and progression of cardiovascular diseases in adults.

Interestingly, the only significant correlation was observed between the changes in adiponectin and the changes in waist circumference after intervention. Waist circumference is used as a safe, easy and inexpensive way to measure abdominal obesity in adults and children, and is considered a good indicator of increased metabolic and cardiovascular risk [36]. According to a previous study, obese children only had an increased metabolic and cardiovascular risk compared with normal-weight children if waist circumference was higher than 90th percentile for age and gender [36]. These findings suggest that during treatment not only a reduction of BMI-SDS but also a lower waist circumference is important to establish a beneficial health effect. In this light, our and previous observations suggest that a significant positive treatment effects on waist circumference over time may be of greater importance for improvement of metabolic risk and cardiovascular risk than weight loss [8].

To the best of our knowledge, no previous study has evaluated the serum concentrations of sTNFR1 and sTNFR2 in obese adolescents. Our present study showed no significant difference in circulating levels of these two receptors between adolescents with obesity and with normal weight. This result is inconsistent with the previous studies in adults. Straczkowski et al. found an increase in both receptors in obese adults compared with lean subjects [8]. In another study by the same author an increase only in sTNFR2 was reported [37]. In contrast, Malavazos et al. showed higher serum TNFR1 in obese women compared with normal weight controls [38]. The different subjects involved in these studies (adolescents or adults) should be taken in consideration for the discrepancy. Moreover, in our current study the serum levels of both receptors did not correlated with any anthropometric parameters, lipid profile, and insulin resistance. In the obese adults, it has been reported that both receptors were associated positively with triglycerides and negatively with HDLcholesterol [8]. Indeed, both receptors are expressed in human adipose tissue but the relative roles of the TNF receptors in adipose tissue remain unclear. TNFR2 expression is greater in subcutaneous adipose tissue from obese females compared to that from lean controls 
[39]. However, increased expression of TNFR2 in adipose tissue does not appear to be associated with central adiposity [40]. Thus further investigation should be involved to clarify their roles in obesity.

Few data are available in the literature on changes in STNFR after lifestyle intervention, and results are controversial. In our study, both receptors did not change significantly after intervention. Similar results have been observed in obese women with polycystic ovary syndrome after energy-restricted diet with $10 \%$ weight loss [41], whereas in other reports, plasma concentrations of sTNFR2 (but not sTNFR1) or plasma concentrations of sTNFR1 (but not in sTNFR2) were decreased significantly after bypass surgery in morbidly obese adults [42]. Possible explanations for such diverse observations may include differences in subject characteristics or the type and duration of treatment type involved in the program.

One limitation of the present study was the absence of a control group at the end of the intervention period to rule out the potential effects of growth on the adipokine response. Previous study showed that serum adiponectin levels decreased with pubertal development in boys and androgens were closely correlated with adiponectin [43]. However, resistin levels showed no differences in gender and pubertal stages [44]. In the present study, no changes of adipokines were observed in the obese adolescents with stable or increased SDSBMI after 6-month intervention. Furthermore no gender differences of lifestyle intervention in adipokines were observed. Thus we can reasonably assume that the lifestyle modification was the main cause of changes in the studied adipokines in the obese subjects with decreased SDS-BMI. Another limitation was no significant weight loss obtained after six-month lifestyle intervention, which may mask the association between changes in adipokines and ameliorated insulin resistance. Finally, the small sample size may also ignore the gender-related difference in adipokines.

In summary, our data showed increased resistin and decreased adiponectin accompanied by insulin resistance in obese adolescents. A six-month lifestyle modification resulted in significant improvement in adipokine abnormalities in obese subjects with decreased SDS-BMI and without any significant changes in both TNF receptors. These results highlight the need for early treatment of adolescent obesity. However, further studies will be needed to improve the understanding of the underlying mechanisms responsible for the obesity-related adipokine profile changes.

\section{Acknowledgments}

We thank Saúl Torres Alcántara, Emma Guadalupe Gazcón Morales, Daniel Chavez Vazquez, Fernando Vega Pineda Fernando, and Sergio Arturo Mavil Cortes for help with blood sample collection and laboratory measures. This work was supported by grants (HIM/2012/002 and HIM/2013/015) from Hospital Infantíl de México Federico Gómez.

\section{Disclosure}

None of the authors has any potential conflicts of interest associated with this research.

\section{References}

1. Northcott JM, Yeganeh A, Taylor CG, Zahradka P, Wigle JT (2012) Adipokines and the cardiovascular system: mechanisms mediating health and disease. Can $J$ Physiol Pharmacol 90: 1029-1059.

2. Li Z, Wang P, Miao C (2011) Adipokines in inflammation, insulin resistance and cardiovascular disease. Clin Exp Pharmacol Physiol 38: 888-896.

3. Kershaw EE, Flier JS. Adipose tissue as an endocrine organ (2004) J Clin Endocrinol Metab 89: 2548-2556.

4. Vendrell J, Broch M, Vilarrasa N, Molina A, Gomez JM, et al. (2004) Resistin, adiponectin, ghrelin, leptin, and proinflammatory cytokines: relationships in obesity. Obes Res 12: 962-971.
5. Gueugnon C, Mougin F, Simon-Rigaud M, Regnard J, Véronique $\mathrm{N}$, et al. (2012) Effects of an in-patient treatment program based on regular exercise and a balanced diet on high molecular weight adiponectin, resistin levels, and insulin resistance in adolescents with severe obesity. Appl Physiol Nutr Metab 37: 672-679.

6. Ten A, Maclaren N (2004) Insulin resistance syndrome in children. J Clin Endocrinol Metab 89: 2526-2539.

7. Beltowski J (2003) Adiponectin and resistin: new hormones of white adipose tissue. Med Sci Monit 9: RA55RA61.

8. Straczkowski M, Kowalska I, Nikolajuk A, Adamska A, Karolczuk-Zarachowicz M, et al. (2006) Plasma levels 
of soluble fumor necrosis factor- $\alpha$ receptors are related to total and LDL-cholesterol in lean, but not in obese subjects. Cardiovasc Diabetol 5: 14.

9. Popkin BM, Gordon-Larsen P (2004) The nutrition transition: worldwide obesity dynamics and their determinants. Int J Obes Relat Metab Disord 28(Suppl 3): S2-S9.

10. Fernandez-Real JM, Broch M, Vendrell J, Ricart W (2003) Smoking, fat mass and activation of the tumor necrosis factor-alpha pathway. Int J Obes Relat Metab Disord 27: 1552-1556.

11. Must A, Jacques PF, Dallal GE, Bajema CJ, Dietz WH (1992) Long-term morbidity and mortality of overweight adolescents. A follow-up of the Harvard Growth Study of 1922-1935. N Engl J Med 327: 1350-1355.

12. Stefanyk LE, Dyck DJ (2010) The interaction between adipokines, diet and exercise on muscle insulin sensitivity. Curr Opin Clin Nutr Metab Care 13: 255-259.

13. Alvarez JA, Higgins PB, Oster RA, Fernandez JR, Darnell BE, et al. (2009) Fasting and postprandial markers of inflammation in lean and overweight children. Am J Clin Nutr 89: 1138-1144.

14. Dehghan M, Akhtar-Danesh N, Merchatnt AT (2005) Childhood obesity, prevalence and prevention. Nutr J 4: 24.

15. Flynn MA, McNeil DA, Maloff B, Mutasingwa D, Wu M, et al. (2006) Reducing obestiy and related chronic disease risk in children and youth: a synthesis of evidence with "best practice" recommendation. Obes Rev 7 Suppl 1: 7-66.

16. Reilly JJ, Wilson D (2006) ABC of obesity: Childhood obesity. BMJ 333: 1207-1210.

17. Huang F, Del-Río-Navarro BE, Pérez-Ontiveros JA, Ruiz-Bedolla E, Navarro-Olivos E, et al. (2013) Changes in ghrelin and asymmetrical dimethylarginine in obese Mexican adolescents after six-month lifestyle intervention. Endocrine 43: 603-610.

18. Huang F, del-Río-Navarro BE, Torres-Alcántara S, Pérez-Ontiveros JA, Pietropaolo- Cienfuegos DR, et al. (2012) Plasminogen activator inhibitor-1, fibrinogen and lung function in adolescents with asthma and obesity. Endocr Res 37: 135-144.

19. Filková M, Haluzik M, Gay S, Senolt L (2009) The role of resistin as a regulator of inflammation: Implications for various human pathologies. Clin Immunol 133: 157170.

20. Li M, Fisette A, Zhao XY, Deng JY, Mi J, et al. (2009) Serum resistin correlates with central obesity but weakly with insulin resistance in Chinese children and adolescents. Int J Obes 33: 424-439.

21. Martos-Moreno GÁ, Barrios V, Martínez G, Hawkins F, Argente J (2010) Effect of weight loss on high-molecular weight adiponectin in obese children. Obesity 18: 2288-2294.

22. Roth CL, Kratz M, Ralston MM, Reinehr T (2011)
Changes in adipose-derived inflammatory cytokines and chemokines after successful lifestyle intervention in obese children. Metab Clin Exp 60: 445-452.

23. Reinehr T, Roth CL, Menke T, Andler W (2006) Resistin concentrations before and after weight loss in obese children. Int J Obes 30: 297-301.

24. Silha JV, Krsek M, Skrha JV, Sucharda P, Nyomba BL, et al. (2003) Plasma resistin, adiponectin and leptin levels in lean and obese subjects: correlations with insulin resistance. Eur J Endocrinol 149: 331-335.

25. Volarova de Courten B, Degawa-Yamauchi M, Considine RV, Tataranni PA (2004) High serum resistin is associated with an increase in adiposity but not a worsening of insulin resistance in Pima Indians. Diabetes 53: 1279-1284.

26. Lee JH, Chan JL, Yiannakouris N, Kontogianni M, Estrada E, et al. (2003) Circulating resistin levels are not associated with obesity or insulin resistance in humans and are not regulated by fasting or leptin administration: cross-sectional and interventional studies in normal, insulin-resistant, and diabetic subjects. $J$ Clin Endocrinol Metab 88: 4848-4856.

27. Many G, Hurtado ME, Tanner C, Houmard J, Uwaifo G, et al. (2013) Moderate-intensity aerobic training program improves insulin sensitivity and inflammatory markers in a pilot study of Morbidly obese minority teens. Pediatr Exerc Sci 25: 12-26.

28. Martos-Moreno GÁ, Barrios V, Martínez G, Hawkins F, Argente J (2010) Effect of weight loss on high-molecular weight adiponectin in obese chidlren. Obesity 18: 2288-2294.

29. Elloumi M, Ounis OB, Makni E, Praagh EV, Tabka Z, et al. (2009) Effect of individualized weight-loss programmes on adiponectin, leptin and resistin levels in obese adolescents boys. Acta Paediatr 98: 1487-1493.

30. Reinehr T, Roth C, Menke T, Andler W (2004) Adiponectin before and after weight loss in obese children. J Clin Endocrinol Metab 89: 3790-3794.

31. Lazzer S, Vermorel M, Montaurier C, Meyer M, Boirie Y (2005) Changes in adipocyte hormones and lipid oxidation associated with weight loss and regain in severely obese adolescents. Int J Obes 29: 1184-1191.

32. Balagopal P, George D, Yarandi H, Funanage V, Bayne E (2005) Reversal of obesity-related hypoadiponectinemia by lifestyle intervention: a controlled, randomized study in obese adolescents. J Clin Endocrinol Metab 90: 6192-6197.

33. Cambuli VM, Musiu MC, Incani M, Paderi M, Serpe $\mathrm{R}$, et al. (2008) Assessment of adiponectin and leptin as biomarkers of positive metabolic outcomes after lifestyle intervention in overweight and obese children. $J$ Clin Endocrinol Metab 93: 3051-3057.

34. Ounis OB, Elloumi M, Amri M, Zbidi A, Tabka Z, et al. (2008) Impact of diet, exercise and diet combined with exercise programs on plasma lipoprotein and adiponec- 
tin levels in obese girls. $J$ Sports Sci Med 7: 437-445.

35. Crujeiras AB, Zulet MA, Lopez-Legarrea P, de la Iglesia R, Pardo M, et al. (2014) Association between circulating irisin levels and the promotion of insulin resistance during the weight maintenance period after a dietary weight-lowering program in obese patients. Metabolism 63: 520-531.

36. Maffeis C, Banzato C, Talamini G (2008) Waist-toheight ratio, a useful index to identify high metabolic risk in overweight children. $J$ Pediatr 152: 207-213.

37. Kirk S, Zeller M, Claytor R, Santangelo M, Khoury PR, et al. (2005) The relationship of health outcomes to improvement in BMI in children and adolescents. Obes Res 13: 876-882.

38. Malavazos AE, Corsi MM, Ermetici F, Coman C, Sardanelli F, et al. (2007) Proinflammatory cytokines and cardiac abnormalities in uncomplicated obesity: relationship with abdominal fat deposition. Nutr Metab Cardiovasc Dis 17: 294-302.

39. Hotamilsligil GS, Arner P, Atkinson RI, Spiegelman BM (1997) Differential regatulation of the p80 tumor necrosis factor receptor in human obesity and insulin resistance. Diabetes 46: 451-455.

40. Good M, Newell FM, Haupt LM, Whitehead JP, Hutley $\mathrm{L}$, et al. (2006) TNF and TNF recptor expression and insulin sensitivity in human omental and subcutaneous adipose tissue-influence of BMI and adipose distribution. Diabetes Vasc Dis Res 3: 26-33.

41. Olszanecka-Glinianowicz M1, Zahorska-Markiewicz B, Kocełak P, Janowska J, Semik-Grabarczyk E (2008) The effect of weight loss on inflammation in obese women with polycystic ovary syndrome. Endokrynol Pol 59: 13-17.

42. Vilarrasa N, Vendrell J, Sánchez-Santos R, Broch M, Megia A, et al. (2007) Effect of weight loss induced by gastric bypass on proinflammatory interleukin-18, soluble tumour necrosis factor-alpha receptors, C-reactive protein and adiponectin in morbidly obese patients. Clin Endocrinol (Oxf) 67: 679-686.

43. Böttner A, Kratzsch J, Müller G, Kapellen TM, Blüher $\mathrm{S}$, et al. (2004) Gender differences of adiponectin levels develop during the progression of puberty and are related to serum androgen levels. J Clin Endocrinol Metab 89: 4053-4061.

44. Martos-Moreno GA, Barrios V, Argente J (2006) Normative data for adiponectin, resistin, interleukin 6 , and leptin/receptor ratio in a healthy Spanish pediatric population: relationship with sex steroids. Eur $J$ Endocrinol 155: 429-434. 